\title{
Editorial
}

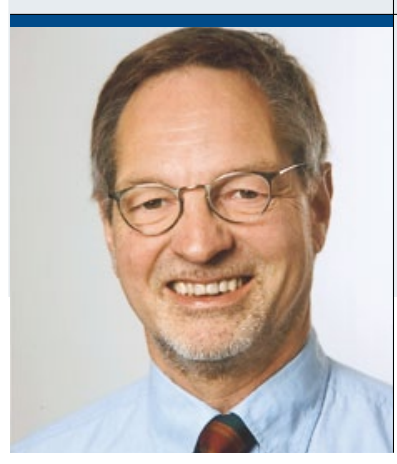

\author{
"Überraschend war, dass der für die „Präsidenten-Pipeline" \\ vom DGU-Präsidium vorgeschlagene Kandidat nicht \\ einfach ,durchgewunken' wurde."
}

Dr. med. Walther Grohmann,

Chefredakteur und niedergelassener Urologe, München

\section{Leipziger Allerlei}

$\mathrm{D}$ er Verlauf der Mitgliederversammlungen der deutschen Gesellschaft für Urologie (DGU) und des Berufsverbandes der Urologen (BDU) in den letzten Jahren hat dazu verführt, selbigen vorab auch für die Versammlung in Leipzig zu prognostizieren (siehe auch Editorial URO-NEWS 10/2012). Doch diesmal verlief es etwas anders.

Neu war die erfreulich hohe Teilnehmerzahl auch von den niedergelassenen Kollegen. Geschuldet war dies offensichtlich dem Antrag auf Satzungsänderung, den federführend der niedergelassene Kollege Dr. Reinhold Schaefer, Bonn, bei der DGU eingebracht hatte. Dieser Antrag ging wesentlich über die vom DGU-Vorstand zur Abstimmung vorgelegte Änderung hinaus. Obwohl korrekt und zeitgerecht eingereicht, wurde er zum Befremden vieler Teilnehmer und trotz Widerspruchs und Hinweis auf juristisch fragwürdiges Vorgehen nicht in die Tagesordnung aufgenommen, sondern per kreativ gehandhabter Geschäftsordnung unter "Verschiedenes" abgehandelt. Der SchaeferAntrag wurde somit erst nach positiver Abstimmung über den DGU-Vorschlag gegen Ende der Versammlung diskutiert - dann allerdings ausgiebig. Der ehemalige BDU-Präsident Dr. Klaus Schalkhäuser war es, der schließlich unter der Maßgabe, der Vorstand der DGU möge sich mit diesem Papier später näher befassen, Antrag auf Schluss der Debatte stellte. Dem wurde zugestimmt, womit zwar ein Teilerfolg erzielt wurde, nicht aber das vom Antragsteller avisierte Ergebnis. Mit dem Antrag sollte die Fachgesellschaft zukunftsfähig gemacht werden. Unter anderem war die Einberufung eines Satzungskonvents vorgesehen, der neue Grundlagen des Miteinanders beraten und beschließen sollte. Eine neue Satzungsvorgabe war angefügt. Wer solche wegweisenden Vorschläge unter "Verschiedenes" abtut, läuft Gefahr, als ignorant angesehen zu werden und als jemand, der als gewählter Inhaber eines Amtes fragwürdig handelt.

Ebenfalls überraschend war, dass der für die „Präsidenten-Pipeline" vom DGU-Präsidium vorgeschlagene Kandidat Prof. Stephan Roth, Wuppertal, nicht einfach „durchgewunken“ wurde: Mehrere Kollegen äußerten in einer Personaldebatte Bedenken gegenüber einer Person, die sich in der Vergangenheit gegenüber niedergelassenen Kollegen wiederholt fragwürdig verhalten habe. Schließlich wurde als weiterer Kandidat Prof. Kurt Miller, Berlin vorgeschlagen, der sich jedoch - zumindest für die jetzt zur Wahl stehende Amtsperiode 2015 - nicht zur Verfügung stellte. Folglich blieb es bei nur einem Kandidaten, der gewählt wurde. So gesehen war alles wie immer (mit Ausnahme 2002).

Die ebenfalls gut besuchte Versammlung des BDU begann mit dem über eine Stunde dauernden Rechenschaftsbericht des Präsidenten Dr. Axel Schroeder und einer Darstellung zur Lage. Inhaltlich waren diese Darlegungen sicher korrekt, für die Zuhörer dank der Langatmigkeit allerdings in jeder Hinsicht „erschöpfend". Die Folge: Einige Neu-Mitglieder - und um die sollte ja intensiv geworben werden - verließen irritiert den Saal. Nicht nur mein Wunsch: Der BDU-Vorstand möge über eine künftig attraktivere und kompaktere Präsentation dieses Tagesordnungs-Punkts intensiv nachdenken. Auch dafür ist ein Präsidium da!

Was bei der eingangs erwähnten DGU-Sitzung noch auffiel: Die Darlegung der DGU-Finanzen, in den vergangenen Jahren kurz, aber in Beträgen detailliert aufgeschlüsselt gezeigt, war Verlaufskurven über die Entwicklung einzelner Bilanzen in den vergangenen Jahren gewichen, ohne dass kontrollierbare "Quellendaten“ gezeigt wurden.

Befremdlich war auch dies: In der Vergangenheit war es gute Sitte der DGU-Mitgliederversammlung, verstorbener Mitglieder angemessen zu gedenken. So hätte in diesem Jahr unter anderem an den ehemaligen DGU-Präsidenten Egbert Schmiedt erinnert werden müssen. Bedauerlicherweise unterblieb dies. Offensichtlich war den Verbänden die eigene Herkunft weniger wichtig als die von ihnen so gesehene Zukunft.

Kurzum: Die Zeiten sind hart, aber modern. Oder: Früher war auch nicht alles besser, aber anders.

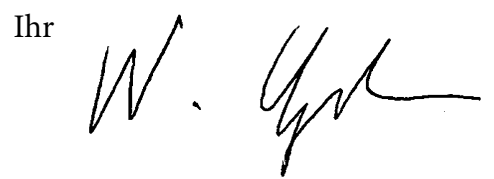

